\title{
VALUING DEVELOPMENTAL CRIME PREVENTION
}

\author{
Matthew Manning, Christine Smith \& Ross Homel \\ Key Centre for Ethics, Law, Justice \& Governance \\ Griffith University
}

To be published in

Criminology and Public Policy, Volume 12, Issue 3, December 2013 


\section{VALUING DEVELOPMENTAL CRIME PREVENTION}

KEYWORDS: Developmental crime prevention, economic analysis, policy making, multi-criteria analysis

\section{Research Summary}

Developmental crime prevention programs produce positive returns on investment. Previous studies of such returns do not adequately quantify and weight impacts across multiple domains of quality of life (e.g., social-emotional development, family wellbeing) or provide a protocol for deciding between programs that recognizes these multiple domains (i.e. propose a method for the ranking of program alternatives). We adapted a multiple criteria decision-making (MCDM) technique to address these deficiencies. Incorporating subjective decisions (a survey of those individuals who directly affect policy decisions) and objective evidence (the effect sizes from a meta-analysis of longitudinal intervention outcomes) allowed us to construct a common metric for making structured choices between diverse developmental crime prevention program options. Our results show that a structured preschool program which incorporates family intervention and support was the most preferred option to reduce youth crime.

\section{Policy Implications}

The adapted MCDM technique employed in this study can be used to evaluate many crime prevention policy options which have effects that are spread across multiple domains and for which objective evidence from past research can usefully be combined with stakeholder judgments to recommend a preferred option. 
Policy that invests in young children promotes equality and social justice as well as improvements in human capital and therefore economic productivity (Heckman, 2006; Careniro and Heckman, 2003; Sen and Nussbaum, 1996). There are particular benefits from programs targeting socially disadvantaged groups because of factors such as a lack of financial resources and poor cognitive and non-cognitive skills (e.g. capacity for concentration, empathy, social skills, and tenacity). Importantly, preventive interventions early in life targeting the most vulnerable have demonstrated positive returns on investment across the life course, both for the individuals concerned and the wider society (Wise et al., 2005; Welsh and Farrington, 2001). Further, well-delivered early prevention programs that are carefully targeted to at-risk groups can produce significantly higher returns on investment than remedial interventions focused on problem behavior or deficiencies in learning (Manning et al., 2006). Interventions aimed at offenders and additional public expenditure on police may also prove to be a less efficient use of public resources than early prevention (Heckman, 2006; Aos et al., 2001; Welsh and Farrington, 2001).

Arguments with respect to the economic benefits of investing in disadvantaged children and the positive rates of return to human capital investment have recently gained momentum, with policy-makers now usually requiring evaluations of efficacy or effectiveness to produce measurements of economic benefits to supplement the non-economic evidence (Cohen et al., 2004). This mandate has seen a number of crime prevention interventions and policies being evaluated using methods such as:

- cost-benefit (e.g., Perry Preschool Project (Belfield et al., 2006; Heckman et al., 2010), and youth justice and family support programs (Lee, et al., 2012));

- cost-savings (e.g. Elmira nurse-family partnership (Olds et al., 1993; Karoly et al., 1998)); and

- cost-effectiveness analyses (e.g. three-strikes law and early interventions (Greenwood et al., 1996)).

The benefits and shortcomings of these methods of economic evaluation have been well critiqued with respect to the placement (or difficulty of placement) of monetary values on outcomes, the types and numbers of outcomes measured, interpretation and generalizability of results, and comparability of results across different programs with varying methodologies (Boardman et al., 2001; Gold et al., 1996; Levin and McEwan, 2001; Manning et al., 2006).

Significant gaps in the economic evaluation of early prevention projects have included:

- the tendency for users of economic methods such as cost-benefit analysis and cost-savings analysis to avoid measuring the less tangible individual benefits resulting from the programs across the life course and across 
multiple domains (Nagin, 2001); for example, improvements in educational success, cognitive development, social-emotional development, family wellbeing, and reductions in deviance, to name a few;

- the lack of a structured protocol for capturing and organizing all of the key elements required for making fully informed policy decisions (Manning, 2008); for example, using results derived from program evaluations, the judgments of expert researchers, practitioners or policymakers or professional experience; and,

- the lack of a common metric for comparing different kinds of interventions (e.g., home visiting, preschools) on a range of indicators linked to later deviance or criminal activity.

This paper aims to address all these deficiencies by using multi-criteria analysis (Mendoza and Macoun, 1999). The adapted method (Manning, 2008) allows one to value improvements in individual wellbeing arising from developmental crime prevention projects, particularly those delivered in the early years, by eliciting relative utility values or preference rankings. The method provides policy makers with a structured protocol for comparing program alternatives directly (using relative utility values/preferences) that incorporates both experience with past interventions and objective evidence (specifically a detailed meta-analysis of the impact of early-in-life interventions on adolescent outcomes (Manning et al., 2010)). Further, this method provides a more comprehensive picture of the impact of interventions on wellbeing across the life course than existing methods. The method generates a common metric outcome or set of common metric outcomes from which policy makers can compare alternative forms of developmental crime prevention programs.

A number of developmental pathways grounded in strong empirical research serve as the theoretical foundation of our policy evaluation tool. From the general perspective of long-term economic growth, developmental interventions delivered early in life affect future human capital formation since they influence, for example, workforce participation (Heckman, 2000). With respect to pathways to adolescent and adult antisocial behavior, Vitaro et al. (2011) propose:

- a behavioral pathway: Early disruptiveness is a predictor of antisocial behavior during adolescence which in turn is an important predictor of adult criminal behavior (Farrington, 1995); and

- a number of socio-environmental pathways, such as:

a) a parental supervision pathway (including positive parenting practices): Lack of such supervision can be linked to adolescent antisocial behavior and can be used to predict later criminal behavior (Larzelere and Patterson, 1990);

b) a peer-related pathway: An association with antisocial deviant peers can nurture an antisocial lifestyle and contact with the criminal justice system (Elliott and Menard, 1996); and 
c) a school-related pathway: School engagement (including being prepared for various transitions such as from preschool to elementary school) is positively correlated with perseverance, school adjustment and school completion. Being prepared to learn, having positive social experiences in school, and ultimately being successful at school (i.e. completing high school) will minimize the chances of adolescent and adult antisocial behavior and engagement in criminal activity (Reynolds et al., 2004).

In the next section we build on these various pathways in summarizing the importance of developmental crime prevention interventions. We also outline the benefits, as proposed by Nagin (2001), which are associated with measuring outcomes of wellbeing and quality of life from an individual perspective. Using data collected from experts who make or contribute to policy in this area, we demonstrate how multi-criteria analysis, specifically the Analytical Hierarchy Process (AHP), can be used to address complex crime prevention policy problems.

\section{The Economic Benefits of Investing Early in Disadvantaged Children}

The National Science Foundation (1994) when announcing its Human Capital Initiative Investing in Human Resources, stated:

...human capital of a nation is a primary determinant of its strength. A productive and educated workforce is a necessity for long-term economic growth. Worker productivity depends on the effective use and development of the human capital of all citizens, which means that schools, families, and neighborhoods must function effectively (p.1).

Savings from investment in disadvantaged communities accrue in the areas of criminal justice (courts, police and corrections), private security (e.g. alarms, private guards, and security systems), urban decay (e.g. lost jobs, relocation of residents), property loss (e.g. stolen goods), medical care (e.g. treating victims of crime), and individual well-being (e.g. pain and suffering, loss of quality of life) (Mandel et al., 1993; Welsh et al., 2001). Moreover, the cost inefficiencies associated with remedial interventions normally delivered to adolescents and young adults (Manning et al., 2006) strengthens the case for investment early in life or at critical points of vulnerability and opportunity later in life.

There is particularly compelling evidence for the effectiveness of evidence-based early prevention directed toward disadvantaged children and their families (Reynolds et al., 2003). Benefits of these programs are sustained well into adolescence and early adulthood in outcome domains as diverse as cognitive development (CD), educational success (ES), social-emotional development (SED), deviance (D), social participation (SP), criminal justice contact (CJ), and family wellbeing (FW) (Manning et al., 2010). What is particularly noteworthy is the strength of effects 10-15 years after 
the initial interventions across all outcome domains and all program types: structured preschool programs, center-based developmental day care, home visitation, family support services and parental education (Figure 1). The average effect sizes in Figure 1 range from 0.157 for SED to 0.528 for ES indicating a significant but small to medium effect size based on Cohen's d. (Cohen, 1992).

\section{Figure 1 about here}

The economic analyses of early prevention point to significant returns on investment (Karoly et al., 2001; Welsh and Farrington, 2001; Lee, et al. 2012). For example, the Perry Preschool program produced rates of return of 15 to 17 percent (Rolnick and Grunewald, 2003), where rate of return was calculated as increments in earning and other outcomes per year for each dollar invested. A cost-benefit analysis of the Perry Preschool project at age 40 revealed that individuals in the treatment group achieved significantly higher earnings. Return on investment to the public included higher tax revenues, lower criminal justice system expenditures, and lower welfare payments. Overall the program returned $\$ 12.90$ as savings for taxpayers/victims for every $\$ 1$ invested (Belfield et al., 2006). A more recent analysis of the rates of return from the High Scope Perry Preschool program estimates annual social rates of return of between seven and ten percent (Heckman et al., 2010), but this study involves a different set of assumptions regarding the tax system than earlier studies. A comparison by Lee et al. (2012) of a range of interventions involving functional family therapy, child support, juvenile justice programs, and pre-kindergarten to grade 12 education demonstrated rates of return ranging from $\$-0.23$ to $\$ 57.79$ for every dollar spent. Similarly a recent follow up of the Chicago Child Parent Centre Program estimated annual rates of return of between 10 and 18 percent (Reynolds et al., 2011). Finally a study by Aos et al. (2012) estimated returns to the state from investment in various forms of evidence-based interventions in Pre K to Year 12 education in the range $\$ 0.22$ to $\$ 24.75$ per dollar spent.

The economic analyses of early prevention programs using cost-benefit, cost-effectiveness and cost-savings methods have been useful in quantifying the direct and indirect economic benefits, but less useful with respect to less readily measured benefits such as improved quality of life. To overcome this deficiency, criminologists occasionally employ cost-utility analysis, a method used in health economics to evaluate the efficacy of a program and to make decisions regarding the allocation of public funds to often competing and disparate program alternatives (Gold et al., 1996). Stemming from this research, and in light of the obvious gaps in understanding the full effects of prevention alternatives, Nagin (2001) reviewed several approaches that would facilitate improvements in the economic methods used to measure the impact of intervention programs on outcomes in both the short- and long-term. He proposed the development of a method that measures benefits across multiple domains, at different times, yet at the individual level. In addition, he 
argued that the methods applied by economists to measure the impact of prevention alternatives do not account for the valuable yet less tangible impacts these programs provide, such as increased public safety, or salient individual benefits, such as improved quality of life. In short, Nagin proposed that the natural unit of analysis in measuring the economic effectiveness of preventive interventions is the individual rather than society. This leads to the search for improvements in a child's and his/her family's quality of life as a result of the intervention.

Following this approach, the analyst needs to identify and quantify the improvements to quality of life resulting from a developmental prevention program in order to create the denominator for cost-utility analysis. Methods such as willingness-to-pay and contingent valuation have been useful in monetizing these improvements, and for estimating the costs of crime (Cohen et al., 2004). These monetized measures have then been incorporated in cost-benefit analyses of crime prevention alternatives.

However, given the richness of meta-analytic data (Manning et al., 2010) regarding diverse early prevention programs and their impacts on various quality of life domains (e.g. educational success and social-emotional development) as given in Figure 1, a multi-stage process for identifying the benefits of early prevention is appropriate. Some results of our metaanalysis are provided in Annex 1. Our adapted AHP method incorporates these results as evidence provided to inform expert decision makers. It also enables ranking of priorities for alternative interventions that are seen as enhancing quality of life, and allows us to identify separately the relative utility (or value) of all the types of outcomes associated with such interventions.

\section{The Analytical Hierarchy Process}

\section{Applying AHP to complex policy decisions regarding skill formation and human capability investment}

Policy makers at all levels of government require multiple criteria to analyze complex problems (Manning, 2008). They can then make trade-offs between achievement on these various criteria highlighting the advantages and disadvantages of different policy options under the veil of risk and uncertainty (Von Neumann and Morgenstern, 1944). For problems such as skill formation and human capability accumulation, trade-offs that serve the common interest are best analyzed via a process that allows for consensus building and compromise (Saaty, 1982). The advantages and disadvantages of using only individual knowledge and experience in decisions concerning welfare and quality of life are well documented by Saaty. He argues that the decision process should display five characteristics: "(1) simple to construct; (2) adaptable to both groups and individuals; (3) natural to our intuition and general knowledge; (4) encourage compromise and consensus building; and, (5) not require inordinate specialization to master and communicate" (Saaty, 1994: 20). 
Decisions regarding human capability investment require answers to questions such as which outcomes are more important than others? How do we weight the often-conflicting aims of human capability investment programs? How do we rank these aims in terms of importance? How can we weight various outcome goals, and how do we bring about these outcomes? Such questions require multi-criteria logic. We argue that in addition, empirical evidence (such as that derived from detailed meta-analysis) should be built into the decision-making framework. The AHP process is one method that can be used to assist with multi-criteria policy decisions. A summary is provided in Figure 2 of the potential benefits of our adapted AHP method (highlighted by the shaded box). In particular, the adapted method generates relative utility values that can be incorporated directly into cost-utility analyses of various intervention alternatives.

\section{Figure 2 about here}

\section{A brief outline of AHP.}

The AHP approach provides a systematic procedure for representing the elements of a decision-making problem, rationally disaggregating the elements into constituent parts, and introducing simple pair-wise comparison judgments for use in developing a vector of weights for ranking alternatives (Saaty, 1980). Providing the expert group who will be asked to make these pairwise comparisons with results from a meta-analytic review of impacts derived from the empirical literature (Manning et al., 2010) has the benefit of allowing these experts to combine subjective elements (real-life experience and feelings) and objective (empirical evidence) elements in the decision-making process.

The AHP method has had extensive application. It has been particularly useful for guiding decisions relating to the allocation of resources (e.g. Chen and Li, 2001a,b), planning (e.g. Yang and Lee, 1997; Crowe et al., 1997; Udo, 2000), impact of policy (e.g. Saaty, 1980, 2001), and resolving conflicts (e.g. Tarbell and Saaty, 1980; Johannessen et al., 2004). The method is also widely applied to corporate planning, portfolio selection, and cost-benefit analysis by government agencies for the purposes of resource allocation (Saaty, 2001).

\section{A Brief Description of the AHP Method.}

The AHP method allows us to rank objectives in terms of their importance with respect to the overall goal or focus, as depicted in the illustrative hierarchy (Figure 3).

Figure 3 about here

A hierarchical structure represents the relationships among the elements at the different levels within the hierarchy (Isard and Smith, 1982; Johannessen et al., 2004). The top of the hierarchy (Saaty, 1990) identifies the goal (e.g. the most 
preferred early childhood prevention program among a group of alternatives). The next level down (Level 1) represents the key actors involved in the decision; Level 2 represents the key objectives of each of the actors; and Level 3 provides the structures that may serve as policy options. More levels may be included in a hierarchy, depending on the problem being analyzed (e.g. complexity, number of objectives). Figure 3 shows that actors A, B, C, D constitute level 1, level 2 represents each actor's objectives $\left(Q_{l}\right.$ and $\left.\mathrm{Q}_{2}\right)$, and level 3 represents potential policy options $(R, S, T)$.

A group of expert respondents is selected to assist in placing values or weights at each level of the hierarchy, taken in turn. For example, each respondent is prompted to compare the objectives $q$ in level $2(q=1 \ldots n)$ in pairs in terms of their relative importance to the achievement of the goal. To compare objective $i$ with objective $j$ we assign the values $q_{i j}$ and $q_{j i}$ such that if $i$ is considered more important than $j$, then $q_{i j}$ is assigned a number greater than unity based on Saaty's comparison scale (Table 1). Judgments are represented on a scale comprising integers from 1 to 9 and their reciprocals (Saaty, 1990, 2000).

\section{Table 1 about here}

This scale is employed to value judgments relating to all possible pairwise comparisons which are represented in a summary matrix $Q$ of dimension $n \times n$ (Table 2). For example the row related to objective 1 in Table 2 can be interpreted as follows: comparing objective 1 to objective 1 gives a value of 1 indicating 'equal importance', comparing objective 1 and objective 3 gives a value of 5 indicating that objective 3 is considered to be of 'essential or strong importance' compared with objective 1 , while comparing objective 1 and objective 2 gives a value of $1 / 3$ indicating that objective 1 is considered to be of 'weak' importance compared with objective 2.

\section{Table 2 about here}

Based on the complexity of the decision, and the number of levels present in the hierarchy we develop a number of such pairwise comparison matrices. From each of these matrices we can compute a normalized vector $\left(\mathrm{Q}^{*}\right)$ of priorities (or relative importance/s). This involves: (a) dividing the elements of each column of the matrix by the sum of that column (normalization of the column); (b) adding the elements in the rows; and (c) dividing this sum by the number of elements in the row (in this case 3 ). The corresponding elements in this column vector $\mathrm{Q}^{*}$ sum to unity. The elements in this vector can thus be interpreted as the respondent's relative weights or priorities for the components of the hierarchy we are comparing.

It is important to check the consistency of respondents' pairwise comparisons. For example, we ask the respondent if he/she prefers $q_{2}$ to $q_{1}$; if $q_{2}$ has greater value than $q_{1}$ we write $q_{2} \succ q_{1}$. If our respondent prefers $q_{1}$ to $q_{3}$, then we write 
$q_{1} \succ q_{3}$. Since $q_{2} \succ q_{1}$ and $q_{1} \succ q_{3}$, logically $q_{2} \succ q_{3}$. This logic of preference is called a transitive property (Isard and Smith, 1982). If the last comparison is $q_{2} \succ q_{3}$, the judgment is consistent. However, if $q_{3} \succ q_{2}$ then the underlying answers are inconsistent. However, 100 percent consistency is not required for the AHP method to be used (Saaty, 2000). Rather a consistency index $(\mathrm{CI})$ is calculated for each pairwise comparison matrix.

This $C I$ is evaluated to determine its acceptability for use in an AHP evaluation by comparing it to a random consistency index $(R I)$ developed by Saaty (1980) to generate a consistency ratio $C R$ test statistic calculated as CI/RI.

As suggested by Saaty, if the value of the $C R$ is smaller or equal to a $10 \%$ tolerance band then the level of inconsistency displayed by the respondent's answers is acceptable. Levels greater than ten percent indicate that we may need to go back to respondents and ask them to reconsider and revise their pairwise comparisons. A full example use of the AHP approach for a 3 level hierarchy such as the one depicted in Figures 3 and 4 is provided in Manning (2008) and Manning et al. (2011).

\section{The Adapted AHP Method}

Our method determines, among the alternatives available, the developmental crime prevention program that is considered, by a sample of experts, to have the most potential to enhance quality of life outcomes (e.g. cognitive development, social-emotional development) and reduce the probability of deviance and contact with the criminal justice system during adolescence. The individuals who populate the study and control groups of the prevention programs described in relevant longitudinal research are considered those most at-risk of poor quality of life outcomes. Such individuals most commonly face risks in four major domains: (1) community ${ }^{\mathrm{i}}$; (2) family ${ }^{\mathrm{ii}}$; (3) peers ${ }^{\mathrm{iii}}$; and (4) individual ${ }^{\mathrm{iv}}$ (Durlak, 1998; Marshall and Watt, 1999; Pollard et al., 1999).

Five forms of early prevention programs are analyzed in this study: structured preschool programs (SPP); home visitation programs (HV); center based childcare/developmental day care (CBCC); family/parent support (FSS); and parent education programs (PE). A full description of these programs is provided in Manning (2008).

Seven outcome domains for disadvantaged populations relating to the impact of these program types during adolescence are included: educational success (ES), cognitive development (CD), social-emotional development (SED), deviance (D), social participation (SP), criminal justice outcomes (CJ) and family well-being (FW). These outcome domains were selected as the focus for the meta-analysis after extensive consultation with academics from criminology, psychology and economics. A full description of these domains is provided in Manning et al. (2010). 
Respondents for the AHP survey were selected on the basis of: (a) their ability to make decisions regarding the implementation of program options available for early prevention; and/or (b) their demonstrated expertise and experience in evaluation of the short- and long-term effectiveness of existing early prevention programs. The selected participants came from four stakeholder groups: policy development personnel (e.g. representatives of Queensland Department of Communities, Department of Child Safety, Queensland Health, Department of Education, Training and the Arts); preschool/school leaders (e.g. school principals, coordinators of childcare centers, and coordinators of crèches and kindergartens); senior community agencies staff (e.g. managers of NGOs involved in community-based developmental prevention programs); and academics expert in developmental crime prevention and early childhood education (Manning, 2008). This methodology has the obvious limitation that the results derived from it are heavily dependent upon, and can be influenced significantly by, the choice of the group of experts selected to provide us with responses to our AHP questions, we adopted a range of strategies to minimize the risks to the validity and generalizability of our findings. First, we cast our net widely for the selection of experts, secondly we involved a steering group or expert panel to oversee our selection, thirdly we obtained our responses from selected experts in strict accordance with an approved human ethics protocol, and finally we conducted a detailed sensitivity analysis of the results to ensure that they were not unduly influenced by the responses of particular individuals. Our sample included most of the key individuals involved in government policy development, academic research, and the policies and practices of community agencies in areas relevant to the research project within Queensland. Nevertheless we regard the results of the survey as illustrative of the potential of the AHP method rather than as definitive. Funds permitting, would seek to expand the sample size in the area of preschool/school leaders in a more exhaustive follow up survey.

Data were collected by conducting two independent surveys. Survey 1 related to the importance of the seven outcome domains (ES, CD, SED, D, SP, CJ, and FW) with respect to their potential contribution to increased non health-related quality of life during adolescence. Preferences among the outcomes were determined by developing a matrix that compared the various outcomes in pairs. We asked participants to express preferences among the intensities of the seven outcomes by developing seven matrices that compared in pairs five outcome levels of success (no impact, small impact, medium impact, large impact, and very high impact) with respect to each outcome. The overall goal was to develop a weighted vector of priorities for program desirability with respect to the most desired outcome intensities. Members of the government policy development group and the academic group were selected to complete Survey 1 , since we expected that they could make the most informed choices based on their expert knowledge of adolescent outcomes associated with developmental crime prevention programs, particularly early-in-life interventions. Furthermore, it was recognized that this group could make expert choices based on their ability to interpret objective results from longitudinal 
research, so they were presented with data derived from the meta-analysis conducted by the authors on the effects of early prevention programs on the seven outcome domains during adolescence (Manning et al., 2010).

Survey 2 aimed to determine the perceived relative contributions of the five early childhood program types (SPP, HV, CBCC, FSS, and PE) with respect to the most desired outcome and intensity combinations derived from Survey 1 . Survey 2 was administered to the school-preschool group and the community agencies group. These participants were also presented with an explanation of the data from the meta-analysis. The decision hierarchy developed for this study is provided in Figure 4.

\section{Figure 4 about here}

The top of the hierarchy represents the overall goal, which is program desirability based on contribution to increasing quality of life and reducing the probability of deviance and contact with the criminal justice system during adolescence. Level 1 represents the domains considered important to achieving the goal (e.g. ES educational success, CD cognitive development). Level 2 highlights five possible intensity levels (no impact (N), small impact (S), medium impact M), large impact (L) and very high impact ( $\mathrm{VH})$ ), which may be associated with the various domains in Level 1. These intensity levels are derived from Cohen $(1992)^{\mathrm{v}}$. Level 3 provides the various early prevention program options (CBCC, SPP, HV, FSS, and PE).

The benefit of this structure is that it allows one to make judgments on the relative importance of each outcome domain, the relative importance of their intensity levels, and ultimately to determine the relative importance or desirability of each possible program option.

\section{Results of the Adapted AHP Method}

Survey 1 consisted of two parts. Part 1 comprised questions about the relative contribution of the seven outcomes to increasing non health-related quality of life during adolescence. The relative priority vector derived from and shown on the right hand side of the pairwise comparisons matrix in Table 3 demonstrates that the outcome FW (family wellbeing) was considered to have the highest priority or level of importance $(0.330)$, followed in order of priority by socialemotional development (SED 0.161) and the other outcomes: SP (0.144), CJ, D, ES and CD.

\section{Table 3 about here}

Table 3 suggests that objective research from the meta-analysis did not greatly influence perceived preferences for outcomes, since the priority weightings were roughly the reverse of the meta-evaluation effect sizes for the seven 
outcome domains in Figure 1 There are probably several reasons for this. First, respondents may have acknowledged that some of the programs were initially developed with a narrow focus on domains such as educational success (ES) and cognitive development (CD). Secondly, had the meta-analytic findings on the outcome domain family wellbeing (FW) not been as limited in terms of the number of longitudinal studies, a much larger weighted mean effect size may have been demonstrated. Thirdly, as MacLeod and Nelson (2000), Nelson et al. (2001), Weissberg and Greenberg (1998), Yoshikawa (1994), and Zigler et al. (1992) argue, multi-component programs in early childhood have more benefits than single program types for children's social-emotional, educational, and cognitive development and for improvements in family wellbeing. Therefore respondents may have been persuaded by current research (Brooks-Gunn et al., 2003; Homel et al., 2006) highlighting the importance of focusing not only on the vulnerable child's school environment but also on their home environment.

Part 2 of Survey 1 comprised questions relating to preferences among the intensities of the outcomes. Seven matrices were developed comparing five intensity levels of success with respect to each of the seven outcomes. Results demonstrated, not surprisingly, that respondents considered a very high effect (VH) most important when selecting a program based on its potential impact, and the outcomes FW (VH-FW) (0.416) and SED (VH-SED) (0.151) were considered the highest priority. This was followed in order of priority by the outcomes VH-SP (0.115), VH-CJ (0.109), VH-D (0.094), VH-ES (0.067) and VH-CD (0.048).

Although a very large effect $(\mathrm{VH})$ on each outcome was considered to be the most important when selecting a program, it does not follow that a lower effect size is of no importance. A close examination of results highlights that participants chose a VH effect size as an ideal potential outcome rather than necessarily a specific criterion for inclusion for potential funding. We suspect that a trade-off between intensity levels of success will probably not occur until each respondent compares the cost of achieving higher and lower levels of effect. Table 4 provides a hypothetical example, where the cost-effectiveness of implementing a program that might achieve large effects (L) on a set of outcomes is almost double that of a program with an anticipated medium effect $(\mathrm{M})$, and almost three times that of funding a program that has the potential to achieve a small effect $(\mathrm{S})$.

\section{Table 4 about here}

Ideally, we would strive to implement programs that have a VH effect on a given set of outcomes. However, when a policy maker is faced with the gamble of funding a program that has a high probability of achieving a small (S) to medium (M) effect on a given set of outcomes with a program that has a lower probability of achieving a VH effect, a trade-off is likely to occur, particularly when costs are incorporated into the decision. This of course will depend upon the 
desired outcomes and the level of importance that the decision maker attaches to each outcome. Moreover, policy makers face the ethical dilemma of choosing between providing a potentially high impact program for a small number of children or funding a program that could potentially have a medium effect on a larger population of children. Rose (1992) conceptualizes this notion as the prevention paradox - where, in terms of a reduction in disease at the population level, a small effect on a large number of people at low risk may be more beneficial overall than a big effect on a small number of people at high risk.

Survey 2 determined the perceived preferences for developmental crime prevention programs by developing seven matrices that compared the five program options in pairs, with respect to the most desired outcome/level of success (VHES, VH-CD, VH-SED, VH-D, VH-SP, VH-CJ, and VH-FW). The results of this survey highlighted that the structured preschool program (SPP) was considered the highest priority (0.320) with respect to contributing to a VH effect on all outcomes during adolescence. This was followed in order of priority by the programs FSS (0.240), PE (0.216), CBCC (0.116), and HV (0.107).

Using the software Expert Choice (Expert Choice, 2000-2004) the level of inconsistency for the hierarchy was 0.06 . This is considered acceptable, since it demonstrates that choices made by respondents were overall relatively consistent, in the sense that they collectively generated a transitive ordering of preferences.

Figure 5 combines the results of the priority rankings from Surveys 1 and 2 . The vector of priorities derived from outcome objectives (ES, CD, SED, D, SP, CJ, and FW) are provided on the $X$-axis (represented by vertical bars). The overall outcome percentage is provided on the left hand $Y$-axis, which ranges from .00 to .90. Program alternatives (SPP, $\mathrm{CBCC}, \mathrm{HV}, \mathrm{FS}$, and PE) are provided on the right hand $Y$-axis, together with the alternative priority percentage, which ranges from .00 to .40 . Overall rankings of program alternatives can be read from the right hand $Y$-axis. The colored lines represent the overall contribution made by the outcomes, in terms of their percentage of priority weighting, to each prevention program alternative.

\section{Figure 5 about here}

Focusing first on the right hand Y-axis, Figure 5 demonstrates that the program alternative structured preschool program SPP rated the highest (32\%). This was followed in order of percentage priority by the program alternatives family support services FSS (24\%), parental education PE (21.6\%), center-based developmental day care CBCC (11.6\%), and home visitation HV (10.7\%). Looking next at the vertical bars, the outcome family wellbeing FW was rated the highest with respect to its potential contribution to improving quality of life during adolescence (33\% of total priority), followed in 
order of priority by the outcomes social-emotional development SED (16.1\%), social participation SP (14.4\%), deviance D (11.3\%), criminal justice contact CJ (11.2\%), educational success ES (7.8\%), and cognitive development CD (6.3\%). Indicators of family wellbeing, the highest rated outcome domain, include strength of familial relationships, level of unity, and overall improved functioning within the family (Children's Home Society and Family Services, 2007).

Figure 5 also allows us to identify which outcomes contributed the most to the percentage priority rankings of the five program alternatives - this is represented by the colored lines showing the overall contribution made by non health-related outcomes, in terms of their percentage of priority, to each program alternative. The colored lines demonstrate a large gap between the outcomes ES, CD, SED and SP, whereby the blue line (representing SPP) lies above the red, brown, khaki, and green lines by a large margin. This shows us that SPP received large priority percentage ratings with respect to the outcomes ES, CD, SED and SP compared with other forms of prevention. In contrast, the red (CBCC program) and green (HV program) lines lie significantly above the other colored lines with regards to deviance (D) and criminal justice outcomes (CJ). Thus, the outcomes D and CJ received rather low priority percentage rankings with respect to their overall contribution to the program alternatives $\mathrm{CBCC}$ and HV. Consequently, these outcomes influenced the overall percentage of priority rankings for $\mathrm{CBCC}$ and $\mathrm{HV}$ with respect to the program alternatives SPP, FSS, and PE.

Sensitivity analyses were conducted to measure the responsiveness of the results to changes in the relative importance of outcome objectives. These analyses demonstrated that results were stable (Manning, 2008).

\section{Conclusion}

This study has illustrated how multi-criteria analysis can be used to rank developmental crime prevention programs. We have argued that crime prevention policy has been formulated for too long without a structured method for carefully assessing the benefits across multiple domains and across diverse policy options, and for incorporating evidence from past experience with such policy options into the method in a meaningful way. A structured method is essential since limitations to human cognitive capacity restrict our ability to capture all the salient information, particularly if one wishes to incorporate multiple domains and the results of a meta-analysis of past experience into the decision-making framework.

The adapted method we have presented and tested in this study provides for better policy decisions by: (1) evaluating program alternatives with respect to priority rankings made by experts in the field; and (2) eliciting individual relative utility values for use in cost-utility analyses of such alternatives. Capturing relative utilities is important as it makes possible an economic approach that values improvements in quality of life resulting from developmental crime 
prevention programs. The outcome domains associated with these improvements are broader, in general, than those incorporated in traditional cost benefit analysis, since our adapted method does not require that attention be restricted to those outcome domains that are readily monetized. In addition the adapted method can be used to identify a set of common metric outcomes across competing and often disparate program alternatives so that decisions can be made which incorporate both the stakeholder perspective and a more holistic individual perspective. Consequently, the approach we have proposed can contribute to a better understanding of the impact of human capability development programs on the most vulnerable children and families.

Nevertheless it should be acknowledged that, as with all methods of policy evaluation, there are weaknesses associated with the AHP approach. These include the issue of rank reversal and hierarchy composition, the axiomatic foundations of the approach, the degree of ambiguity in the questions asked of respondents, possible selection bias around choice of respondents, and the scale used to measure the intensity of preferences. Detailed discussions of these weaknesses may be found in Harker and Vargas (1987, 1990), McCaffrey (2005), Manning (2008), and Warren (2004).

The methods proposed in this paper could be improved if developmental crime prevention programs incorporated other relevant indicators for the seven outcome domains, especially aspects of family wellbeing that were so highly valued by respondents in the present study. Elements such as length and intensity of programs, the use of follow-up programs, multi component programs, and multi-contextual programs could also be incorporated. Additionally, future research could expand the survey participant base to incorporate national and international perspectives.

Finally the adapted method developed in this study could be used to evaluate crime prevention policy options being considered for adoption in other areas. For example see Manning, et al. (2013) for an application of the method in developing policy for controlling access to illegal precursor chemicals in the production of methamphetamine. The method could also be used with profit to evaluate the kinds of widely used 'no name' youth offender treatment programs proposed by Lipsey and Howells (2012) as evidence-based alternatives to the 'model programs' that are at the center of current efforts to transform science into service (Fixsen et al., 2009; Smith et al., 2009) as well as the alternative rehabilitation treatment programs advocated by leaders in the principles of effective intervention literature (e.g. Gendreau, 1996; Lowenkamp, et al., 2006; and Smith, et al., 2009). 


\section{References}

Aos, Steve, Polly Phipps, Robert Barnoski, and Roxanne Lieb. 2001. The comparative costs and benefits of programs to reduce crime: a review of research findings with implications for Washington State. In (Brandon Welsh, David Farrington and Lawrence Sherman,eds.), Costs and benefits of preventing crime. Boulder, CO: Westview Press.

Belfield, Clive R., Milagros Nores, Steve W. Barnett, and Lawrence J. Schweinhart. 2006. The High/Scope Perry Preschool Program: Cost-benefit analysis using data from the age-40 followup. Journal of Human Resources, 41:162190.

Berrueta-Clement, John R., Lawrence J. Schweinhart, Steve W. Barnett, Ann S. Epstein, and David P. Weikart. 1984. Changes lives: The effects of the Perry Preschool Program on youths through age 19. Ypsilanti, MI: High/Scope Educational Research Foundation.

Boardman, Anthony E., David H. Greenberg, Adrian R. Vining, and David L. Weimer. 2001. Cost-benefit analysis: Concepts and practice. 2nd ed. Upper Saddle River, NJ: Prentice Hall.

Brooks-Gunn, Jeanne, Alison S. Fuligni, and Lisa J. Berlin. 2003. Early child development in the 21st century : Profiles of current research initiatives. London: Teachers College Press.

Campbell, Frances .A. and Craig T. Ramey. 1994. Effects of early intervention on intellectual and academic achievement: A follow-up study of children from low-income families. Child Development, 65:684-698.

1995. Cognitive and school outcomes for high-risk African-American students at middle adolescence: Positive effects of early intervention. American Educational Research Journal, 32:743-772.

Campbell, Frances A., Craig T. Ramey, Elizabeth Pungello, Joseph Sparling, and Shari Miller-Johnson. 2002. Early childhood education: Young adult outcomes from the Abecedarian Project. Applied Developmental Science, 6:42-57.

Carneiro, Pedro and James Heckman. 2003. Human capital policy. In (J. Heckman, A. Krueger and B. Friedman, eds.), Inequality in America. Cambridge, MA: MIT Press.

Chen, Eddie W.L., and Heng. Li. 2001a. Analytical Hierarchy Process: An approach to determine measures for business performance. Measuring Business Excellence, 5:30-36. 
- 2001b. Information priority-setting for better resource allocation using analytic hierarchy process (AHP). Information Management \& Computer Security, 9:61-70.

Children's Home Society and Family Services. 2007. Child and family support services. Retrieved 20 April 2007, from http://www.chsfs.org/Child_Family_Support_Services.html

Cohen, Jacob. 1992. Quantitative methods in psychology: A power primer. Psychological Bulletin, 112:155-159.

Cohen, Mark, Roland Rust, Sara Steen, and Simon Tidd. 2004. Willingness-to-pay for crime control programs.

Criminology, 42:89-109.

Crowe, Thomas J., James S. Noble, and Jeevan S. Machimada. 1997. Multi-attribute analysis of the ISO 9000 registration using AHP. International Journal of Quality \& Reliability Management, 15:205-222.

Durlak, Joseph. 1998. Common risk and protective factors in successful prevention programs. American Journal of Orthopsychiatry, 68:512-520.

Eckenrode, John, Barbara Ganzel, Charles R. Henderson, Elliot Smith, David Olds, Jane Powers, Robert Cole, Harriet Kitzman, and Kimberley Sidora. 2000. Preventing child abuse and neglect with a program of nurse home visitation, 284:1385-1391.

Elliott, Delbert and Scott Menard. 1996. Delinquent friends and delinquent behaviour: Temporal and developmental patterns. In (J. David Hawkins, ed.), Delinquency and crime. Cambridge, UK: Cambridge University Press.

Expertchoice. 2000-2004. Expert Choice Inc., Arlington, VA, USA.

Farrington, David. 1995. The twelfth Jack Tizard Memorial Lecture: The development of offending and antisocial behaviour from childhood: Key findings from the Cambridge Study in delinquent development. The Journal of Child Psychology and Psychiatry, 36:929-964.

Gendreau, Paul (1996). The principles of effective interventions with offenders. In (Alan Harland, ed.), Choosing correctional options that work: Defining the demand and evaluating the supply. Thousand Oaks, CA: Sage.

Gold, Marthe R., Donald L. Patrick, George W. Torrance, Dennis G. Fryback, David C. Hadorn, Mark S. Kamlet, Norman Daniels, and Milton C. Weinstein. 1996. Identifying and valuing outcomes. In Marthe R. Gold, Joanna E. Siegel, 
Louise. B. Russell and Milton C. Weinstein (eds.) Cost-effectiveness in health and medicine. New York, NY: Oxford University Press.

Fixsen, D., Blase, K., Naoom, S., \& Wallace, F. (2009). Core implementation components. Research on Social Work Practice, 19(5), 531-540.

Gray, Susan W. and Rupert A. Klaus. 1970. The Early Training Project: A seventh-year report. Child Development, 41:909-924.

Greenwood, Peter, Karyn Model, C. Peter Rydell, and James Chiesa. 1996. Diverting children from a life of crime: Measuring costs and benefits. Santa Monica, CA: RAND Corporation.

Harker, Patrick T. and Vargas, Luis. G. 1987. The theory of ratio estimation: Saaty's analytic hierarchy process. Management Science, 33(11), 1383-1404.

Harker, Patrick T. and Vargas, Luiz. G. 1990. Reply to "Remarks on the analytic hierarchy process" by J.S. Dyer. Management Science, 36(3), 269-273.

Heckman, James. 2000. Policies to foster human capital. Research in Economics, 54:3-56. 2006. Skill formation and the economics of investing in disadvantaged children. Science, 312:1900-1902.

Heckman, James, Seong H. Moon, Rodrigo Pinto, Peter Savelyev and Adam Yavitz. 2010. A new cost benefit and rate of return analysis for the Perry Preschool Program: A summary. Cambridge, MA: National Bureau of Economic Research.

Homel, Ross, Kate Freiberg, Cherie Lamb, Marie Leech, Angela Carr, Anne Hampshire, Ian Hay, Gordon Elias, Matthew Manning, Rosie Teague, and Sam Batchelor. 2006. The Pathways to Prevention Project: The first five years 1999-2004. Brisbane: Griffith University and Mission Australia.

Isard, Walter and Christine Smith. 1982. Conflict analysis and practical conflict management: An introduction to peace science. Cambridge, MA: Ballinger Publishing Company.

Johannessen, Preben, Jayatilleke S. Bandara, and Christine Smith. 2004. An analysis of the Sri Lankan conflict using an economic tool. Economic Analysis and Policy, 33:163-188. 
Johnson, Dale L. 2006. Parent-Child Development Center follow-up project: Child Behavior problem results. The Journal of Primary Prevention, 27:391-407.

Johnson, Dale L. and Janet Blumenthal. 2004. The Parent Child Development Centres and school achievement. The Journal of Primary Prevention, 25:195-209.

Karoly, Lynn, Peter Greenwood, Susan Everingham, Jill Hoube, Rebecca Kilburn, Peter Rydell, Matthew Sanders, and James Chiesa. (1998). Investing in Our Children: What We Know and Don't Know about the Costs and Benefits of Early Childhood Interventions. RAND, Santa Monica, CA.

Karoly, Lynn, Rebecca Kilburn, James Bigelow, Jonathan Caulkins, and Jill Cannon. 2001. Assessing costs and benefits of early childhood intervention programs: Overview and application to the Starting Early Starting Smart program. Seattle, WA: Casey Family Programs.

Lally, J. Ronald, Peter L. Mangione, and Alice S. Honig. 1988. The Syracuse University Family Development Research Program: Long-range impact on an early intervention with low-income children and their families. In (Douglas R. Powell, ed) Parent education as early childhood intervention: Emerging directions in theory, research and practice. Norwood, NJ: Ablex Publishing Corporation.

Larzelere, Robert and Gerald Patterson. 1990. Parental management: Mediator of the effect of socioeconomic status on early delinquency. Criminology, 28:301-323.

Lazar, Irving, Richard Darlington, Harry Murray, Jacqueline Royce, Ann Snipper, and Craig T. Ramey. 1982. Lasting effects of early education: A report from the Consortium for Longitudinal Studies. Monographs of the Society for Research in Child Development, 47:1-151.

Lee, Stephanie, Steve Aos, Elizabeth Drake, Annie Pennucci, Marna Miller, and Laurie Anderson. (2012). Return on investment: Evidence-based options to improve statewide outcomes. Olympia: Washington State Institute for Public Policy.

Levenstein, Phyllis, Susan Levenstein, James A. Shiminski, and Judith E. Stolzberg. 1998. Long-term impact of a verbal interaction program for at-risk toddlers: An exploratory study of high school outcomes in a replication of the MotherChild Home Program. Journal of Applied Developmental Psychology, 19:267-285.

Levin, Henry M. and Patrick J. McEwan. 2001. Cost-effectiveness analysis. 2nd ed. London: Sage Publications. 
Lowenkamp, Christopher T., Edward Latessa and Paula Smith (2006). Does correctional program quality really matter? The impact of adhering to the principles of effective intervention. Criminology and Public Policy, 5(3), 575-594.

MacLeod, Jennifer and Geoffrey Nelson. 2000. Programs for the promotion of family wellness and the prevention of child maltreatment: A meta-analytic review. Child Abuse and Neglect, 24:1127-1149.

Mandel, Michael, Paul Magnusson, James Ellis, Gail DeGeorge, and Keith Alexander. 1993. The economics of crime. Business Week, December 13:72-75.

Manning, Matthew. 2008. Economic evaluation of the effects of early childhood intervention on adolescent outcomes. $\mathrm{PhD}$, Key Centre for Ethics, Law, Justice and Governance, Griffith University, Brisbane

Manning, Matthew, Janet Ransley, Christine Smith, Lorraine Mazerolle and Alana Cook. 2013. Policing Methemphetamine Problems: A Framework for Synthesising Expert Opinion and Evaluating Alternative Policy Options, Journal of Public Policy, 33(2) in press.

Manning, Matthew, Ross Homel, and Christine Smith. 2006. Economic evaluation of a community-based early intervention program implemented in a disadvantaged urban area of Queensland. Economic Analysis and Policy, 36:99120.

2010. A meta-analysis of the effects of early developmental prevention programs in at-risk populations on nonhealth outcomes in adolescence. Children and Youth Services Review, 32:506-519.

Manning, Matthew, Christine Smith, and Ross Homel. 2011. An economic method for formulating better policies for child development. Australian Review of Public Affairs, 10:61-77.

Marshall, Jann, and Paula Watt. 1999. Child behaviour problems: A literature review of the size and nature of the problem and prevention interventions in childhood. Perth, Western Australia: The Interagency Committee on Children's Futures.

McCaffrey, James. 2005. Tests run: The analytical hierarchy process. MSDN Magazine.

Mendoza, Guillermo and Phil Macoun. 1999. Guidelines for applying multi-criteria analysis to the assessment of criteria and indicators. Indonesia: Centre for International Forestry Research (CIFOR). 
Meyer, Linda A. 1984. Long-term academic effects of the Direct Instruction Project Follow Through. The Elementary School Journal, 84:380-394.

Miller, Louise and Rhondeall P. Bizzell. 1983. Long-term effects of four preschool programs: Sixth, seventh, and eighth grades. Child Development, 54:727-741.

Nagin, Daniel. 2001. Measuring the economic benefits of developmental prevention programs. In (M. Tonry, ed.) Crime and Jusice: A Review of Research. Chicago, IL: The University of Chicago Press.

National Science Foundation. 1994. Investing in human resources. Arlington, VA: National Science Foundation.

Nelson, Geoffrey, Marie-Claire Laurendeau, Claire Chamberland, and Leslea Peirson. 2001. A review and analysis of programs to promote family wellness and prevent the maltreatment of preschool and elementary school aged children. In (Isaac Prilleltensky, Geoffrey Nelson and Leslea Peirson, eds.) Promoting family wellness and preventing child maltreatment: Fundamentals for thinking and action. Toronto: University of Toronto Press.

Olds, Dennis, Charles R. Henderson, Robert Cole, John Eckenrode, Harriet Kitzman, Dennis Luckey, Lisa Pettitt, Kimberley Sidora, Pamela Morris, and Jane Powers. 1998. Long-term effects of nurse home visitation on children's criminal and antisocial behaviour. Journal of the American Medical Association, 280:1238-1244.

Olds, Dennis, Charles R. Henderson, Charles Phelps, Harriet Kitzman, and Carole Hanks. 1993. Effects of prenatal and infancy nurse home visitation on government spending. Medical Care, 31:155-174.

Pollard, John, J. David Hawkins, and Michael Arthur. 1999. Risk and protection: Are both necessary to understand diverse behavioural outcomes in adolescence? Social Work Research, 23:145-158.

Reynolds, Arthur. J. 1994. Effects of a preschool plus follow-on intervention for children at-risk. Developmental Psychology, 30:787-804.

Reynolds, Arthur J., Judy A Temple, Dylan L Robertson, and Emily A Mann. 2001. Long-term effects of an early childhood intervention on educational achievement and juvenile arrest: A 15 year follow-up of low income children in public school. Journal of the American Medical Association, 285. 
Reynolds, Arthur, Suh-Ruu Ou, and Joshua Topitzes. 2004. Paths of effects of early childhood intervention on educational attainment and delinquency: A confirmatory analysis of the Chicago Child-Parent Centres. Child Development, 75:1299-1328.

Reynolds, Arthur, Judy Temple, Barry White, Suh-Ruu, Ou, and Dylan Robertson. 2011. Age 26 cost-benefit of the Child-Parent Center Early Education Program. Child Development, 82 (1), 379-404.

Reynolds, Arthur, Margaret Wang, and Herbert Walberg. 2003. Early childhood programs for a new century.

Washington, D.C: Child Welfare League of America Press.

Rolnick, Arthur and Rob Grunewald. 2003. Early childhood development: Economic development with a high public return. Minneapolis, MN: Federal Reserve Bank of Minneapolis.

Rose, Geoffrey. 1992. The strategy of preventive medicine. Oxford: Oxford University Press.

Saaty, Thomas L. 1980. The analytic hierarchy process. New York: McGraw-Hill.

1982. How to make a decision: The Analytic Hierarchy Process. Interfaces, 24:19-43.

1986. Axiomatic foundation of the analytic hierarchy process. Management Science, 32:841-855.

1990. Multicriteria decision making: The Analytical Hierarchy Process. Pittsburgh, PA: RWS Publications.

1994. How to make a decision: the analytic hierarchy process. Interfaces, 24:19-43.

2000. Fundamentals of decision making and priority theory. 2nd ed. Pittsburgh, PA: RWS Publications.

2001. Decision making for leaders. 3rd ed. Pittsburg, PA: RWS Publications.

Sen, Amartya, and Martha Nussbaum. 1996. Functioing and capability: The foundation of Sen's and Nussbaum's development of ethic. Political Theory, 24:584-612.

Smith, Paula, Paul Gendrea and Kristen Swartz. 2009. Validating the principles of effective intervention: A systematic review of the contributions of meta-analysis in the field of corrections. Victims \& Offenders: An International Journal of Evidence-Based Research, Policy, and Practice, 4(2), 148-169. 
Sprigle, Joan E. and Lynn Schaefer. 1985. Longitudinal evaluation of the effects of two compensatory preschool programs on fourth- through sixth-grade students. Developmental Psychology, 21:702-708.

Tarbell, David S. and Thomas L. Saaty. 1980. The conflict in South Africa. Journal of Peace Science, 4:151-168.

Udo, Godwin G. 2000. Using analytical hierarchy process to analyze the information technology outsourcing decision. Industrial Management \& Data Systems, 100:421-429.

Vitaro, Frank, Edward Barker, Mara Brendgen, and Richard Tremblay. 2011. Pathways explaining the reduction of adult criminal behaviour by a randomized preventive intervention for disruptive kindergarten children. The Journal of Child Psychology and Psychiatry, 53: 748-56.

Von Neumann, John and Oscar Morgenstern. 1944. Theory of Games and Economic Behavior. Princeton, NJ: Princeton University Press.

Warren, Lewis. (2004). Uncertainties in the Analytic Hierarchy Process. South Australia: Defence Science and Technology Organisation.

Weissberg, Roger P. and Mark T. Greenberg. 1998. School and community competence-enhancement and prevention programs. In (William Damon, Irving E. Sigel and K. Ann Renninger, eds.) Handbook of child psychology. New York, NY: Wiley.

Welsh, Brandon and David Farrington. 2001. Assessing the economic costs and benefits of crime prevention. In (B.

Welsh, D. Farrington and L. Sherman, eds.) Costs and benefits of preventing crime. Boulder, CO: Westview Press.

Welsh, Brandon, David. Farrington, and Lawrence Sherman, eds. 2001. Costs and benefits of preventing crime. Boulder, CO: Westview Press.

Wise, Sarah, Lisa da Silva, Elizabeth Webster, and Ann. Sanson. 2005. The efficacy of early childhood interventions. Canberra, ACT: Australian Institute of Family Studies.

Yang, Jiaquin and Huei Lee. 1997. An AHP decision model for facility location selection. Facilities, 15:241-254.

Yoshikawa, Hirokazu. 1994. Prevention as cumulative protection: Effects of early family support and education on chronic delinquency and its risks. Psychological bulletin, 115:28-54. 
Zigler, Edward, Cara Taussig, and Kathryn Black. 1992. Early childhood intervention: A promising preventative for juvenile delinquency. American Psychologist, 47:997-1006. 
Figure 1. Weighted Average Effect Sizes (d.) Corrected for Sample Size for Seven Adolescent Outcome Domains (ES, CD, SED, D, SP, CJ, FW)

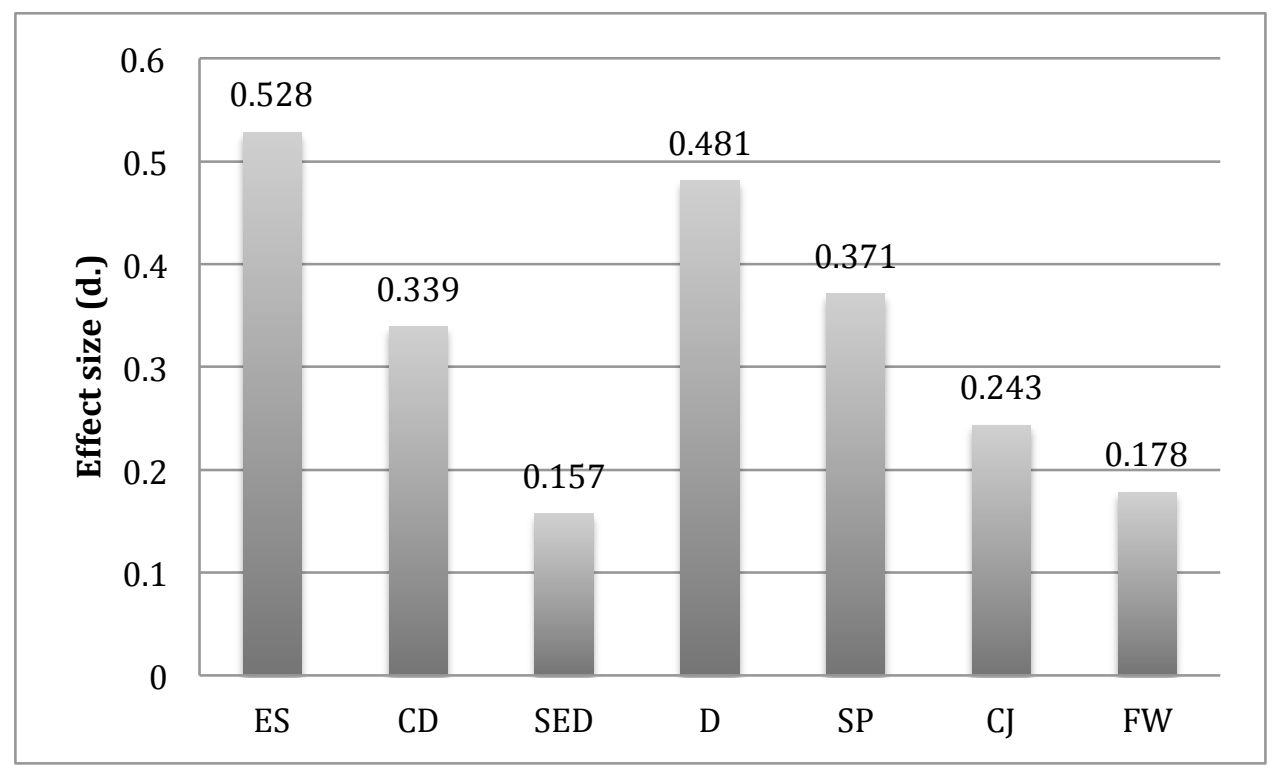

Notes: 1. Cohen's d. is used to move beyond only knowing that a difference exists between populations tested (i.e. hypothesis testing) to identifying the strength and magnitude of a difference between two populations. Briefly, Cohen's d. is calculated by dividing the mean difference between populations by the standard deviation; where: a result of $0.2=$ small effect; 0.5 = medium effect; and 0.8 = large effect (Cohen, 1992). 2. The follow-up periods for the studies incorporated in the meta-analysis from which these $d$. values have been calculated were on average 10-15 years after the intervention, that is they were follow-ups on adolescents who had been the subject of an early childhood intervention.

Source: Manning et al. (2010). 
Process Repetition: Enables people to refine their definition of a problem and to improve their judgment and understanding through repetition

Judgment and Consensus: AHP does not insist on consensus but synthesizes a representative outcome from diverse judgments

Tradeoffs: AHP considers the relative priorities of factors in a system \& enables people to select the best alternative according to their goals

Synthesis: AHP leads to an overall estimate of the desirability of each alternative

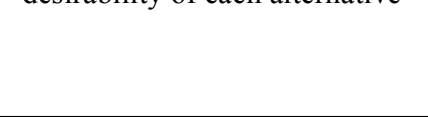

Consistency: AHP tracks the logical consistency of judgments used in determining priorities
Unity: Provides a single, easily understood, flexible model for a range of unstructured problems
Complexity: Integrates deductive and system approaches in solving complex problems

Interdependence: AHP deals with the interdependence of elements in a system; does not rely on linear thinking

Hierarchic Structure: AHP reflects the natural tendency of the human mind to sort elements of a system into different levels and group like elements in each level

Measurement: AHP provides a scale for measuring intangibles and a method for establishing priorities

\footnotetext{
Source: Adapted from Saaty (2001).
} 
Figure 3. An Illustrative Hierarchy

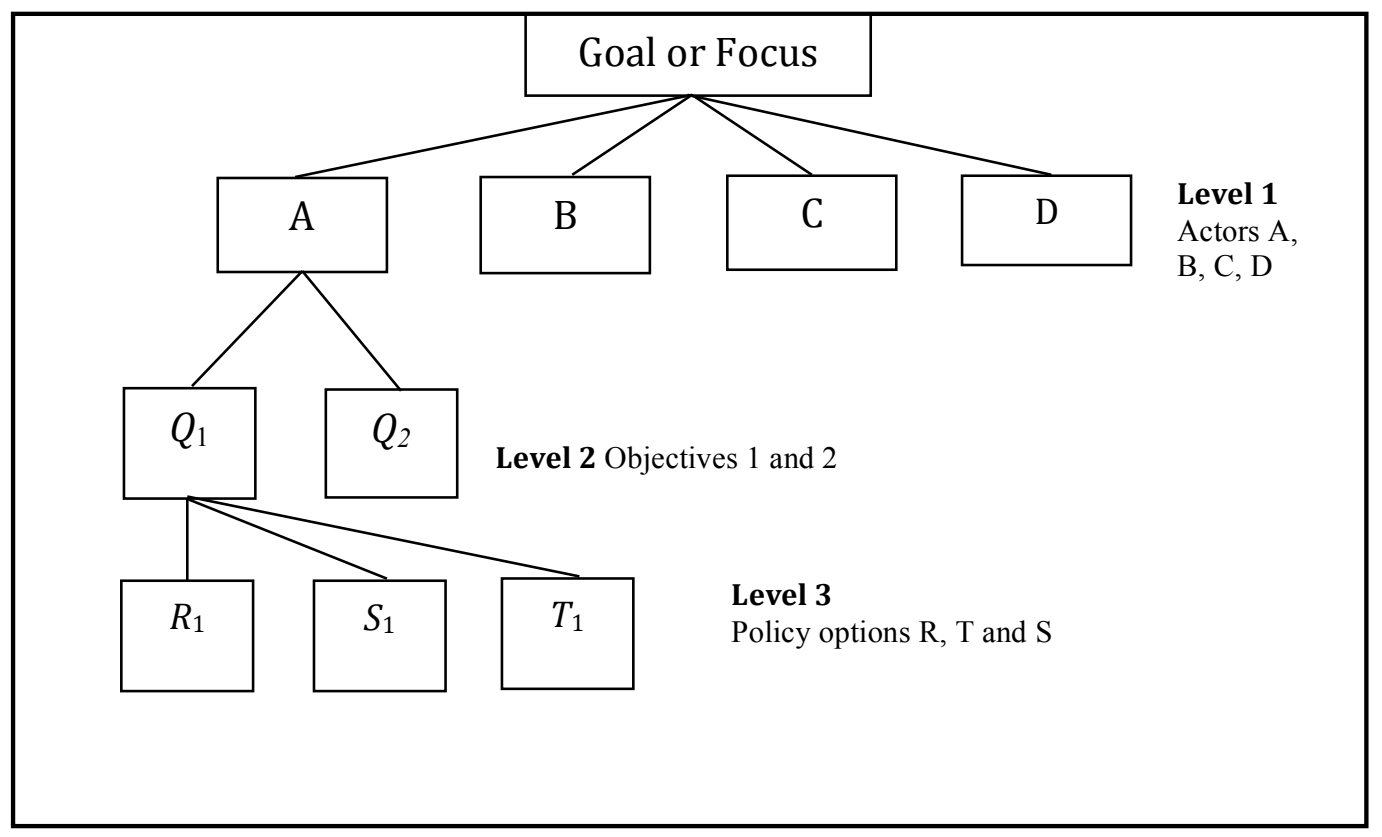

Source: Manning (2008). 
Figure 4. Decision Hierarchy for Human Capital Program Alternatives, Outcome Domains and Level of Effect

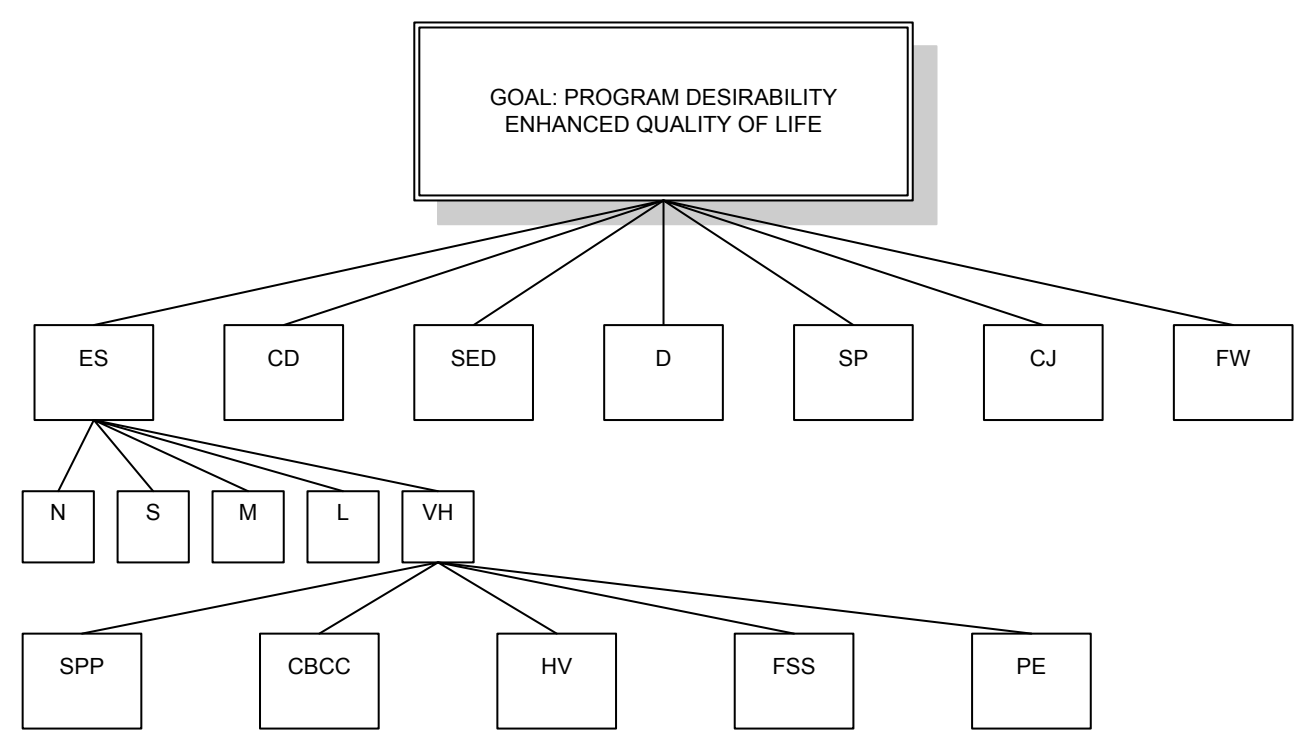

LEVEL 1: ES = Education success; CD

$=$ Cognative development; SED = Social-

emotional development; $\mathrm{D}=$ Deviance; $\mathrm{SP}=$

Social participation; $\mathrm{CJ}=$ Criminal justice

outcomes; FW = Family wellbeing.

LEVEL 2: $N=$ No impact $(E S=0) ; S=$ Small impact $(E S=0.20)$; Medium impact $(E S=0.50)$; $\mathrm{L}=$ Large impact $(\mathrm{ES}=0.80) ; \mathrm{VH}=$ Very high impact $(E S=>0.80)$.
LEVEL 3: SPP = Structured preschoo program; $\mathrm{CBCC}=$ Centre-based childcare/ developmental day care; $\mathrm{HV}=\mathrm{Home}$

visitation; FSS = Family support services; PE $=$ Parental education

Source: Manning (2008). 
Figure 5. Overall Performance Graph for Hierarchy

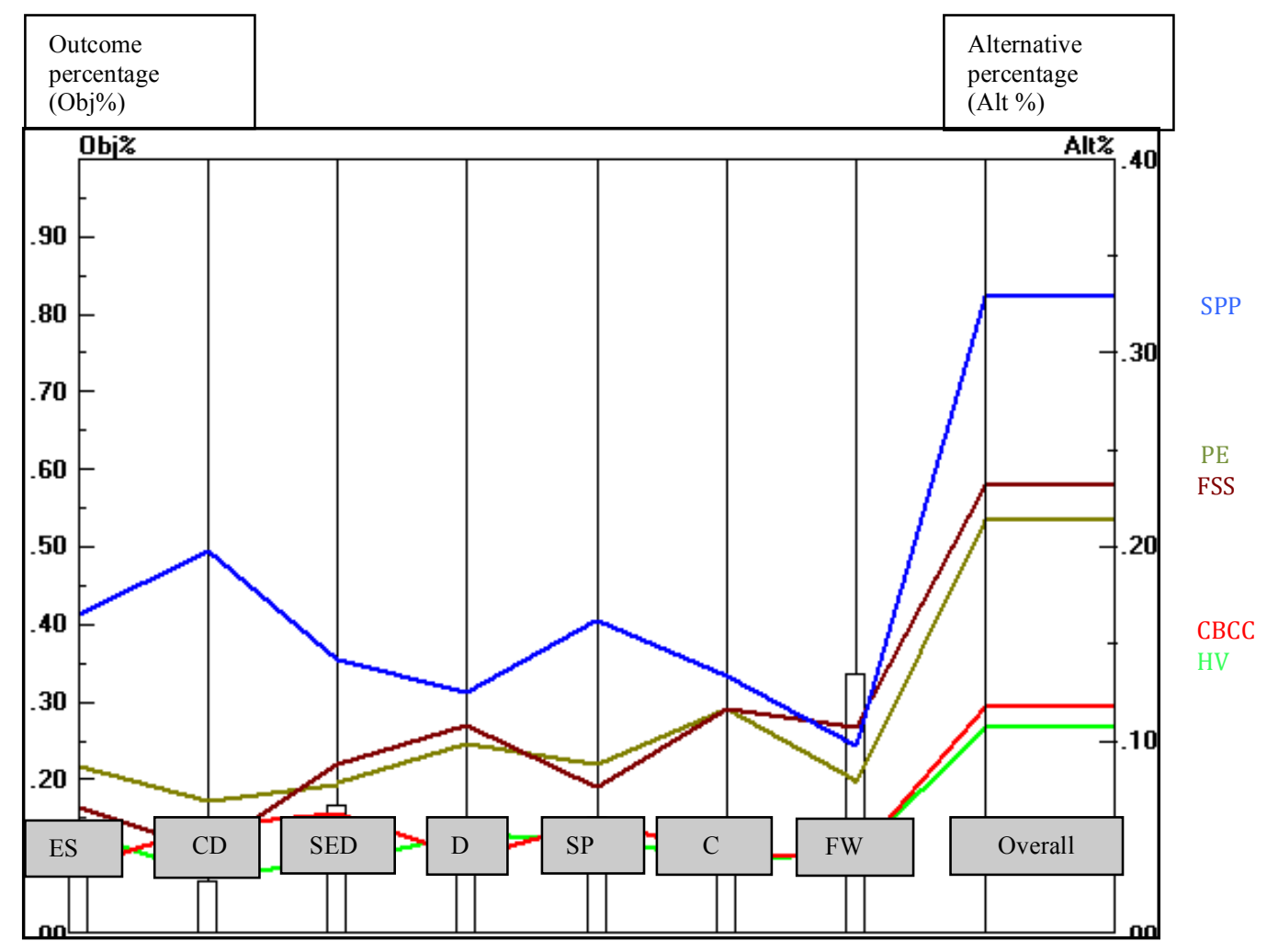

Source: Manning (2008). 
Table 1. Saaty's Comparison Scale

\begin{tabular}{lll}
\hline Intensity of Importance & Definition & Explanation \\
\hline 1 & Equal importance & $\begin{array}{l}\text { Two elements are of equal } \\
\text { importance }\end{array}$ \\
3 & Weak importance & $\begin{array}{l}\text { Experience and judgment } \\
\text { slightly favor one element over } \\
\text { another }\end{array}$ \\
5 & Essential or strong importance & $\begin{array}{l}\text { Experience and judgment } \\
\text { strongly favor one element over } \\
\text { another }\end{array}$ \\
7 & Demonstrated or very strong & $\begin{array}{l}\text { An element is strongly favored } \\
\text { and its dominance is } \\
\text { demonstrated in practice }\end{array}$ \\
9 & importance & $\begin{array}{l}\text { The evidence favoring one } \\
\text { element over another is of the } \\
\text { highest possible affirmation }\end{array}$ \\
& & Absolute importance \\
$\mathbf{2 , 4 , 6 , 8}$ & Intermediate values & When compromise is needed \\
\hline
\end{tabular}

Adapted from: Saaty (1990). 
Table 2. Example of Pairwise Comparisons of Objectives $\left(q_{1}, q_{2}, q_{3}\right)$

\begin{tabular}{ccccc}
\hline & $q_{1}$ & & $q_{2}$ & $q_{3}$ \\
\hline$q_{1}$ & 1 & $1 / 3$ & 5 \\
$q_{2}$ & & 1 & 7 \\
$q_{3}$ & & & 1 \\
\hline
\end{tabular}

Adapted from: Saaty (1980). 
Table 3. Pair-Wise Comparison of Adolescent Outcomes (Average Response)

\begin{tabular}{|c|c|c|c|c|c|c|c|c|}
\hline & ES & $\mathrm{CD}$ & SED & $\mathrm{D}$ & $\overline{\mathrm{SP}}$ & CJ & FW & \\
\hline ES & 1.00 & 0.79 & 0.30 & 0.52 & 1.08 & 0.89 & 0.28 & \\
\hline $\mathrm{CD}$ & $\begin{array}{r}1.27 \\
(1.42)\end{array}$ & 1.00 & 0.28 & 0.42 & 0.58 & 0.39 & 0.26 & $\begin{array}{l}\text { ES } \\
0.078\end{array}$ \\
\hline SED & $\begin{array}{r}3.33 \\
(2.36)\end{array}$ & $\begin{array}{r}3.55 \\
(2.43)\end{array}$ & 1.00 & 0.84 & 0.70 & 1.02 & 0.78 & $\begin{array}{l}\text { CD } \\
0.063\end{array}$ \\
\hline D & $\begin{array}{r}1.92 \\
(2.44)\end{array}$ & $\begin{array}{r}2.36 \\
(3.10)\end{array}$ & $\begin{array}{r}1.19 \\
(1.90)\end{array}$ & 1.00 & 0.37 & 0.99 & 0.23 & $\begin{array}{l}\text { SED } \\
0.161\end{array}$ \\
\hline SP & $\begin{array}{r}0.93 \\
(1.46)\end{array}$ & $\begin{array}{r}1.73 \\
(1.90)\end{array}$ & $\begin{array}{r}1.43 \\
(1.73)\end{array}$ & $\begin{array}{r}2.71 \\
(2.38)\end{array}$ & 1.00 & 1.19 & 0.28 & $\begin{array}{l}\mathbf{D} \\
0.113\end{array}$ \\
\hline CJ & $\begin{array}{r}1.12 \\
(1.92)\end{array}$ & $\begin{array}{r}2.54 \\
(2.50)\end{array}$ & $\begin{array}{r}0.98 \\
(1.20)\end{array}$ & $\begin{array}{r}1.01 \\
(1.11)\end{array}$ & $\begin{array}{r}0.84 \\
(1.14)\end{array}$ & 1.00 & 0.29 & $\begin{array}{l}\text { SP } \\
0.144\end{array}$ \\
\hline FW & $\begin{array}{r}3.63 \\
(2.63)\end{array}$ & $\begin{array}{r}3.90 \\
(1.60)\end{array}$ & $\begin{array}{r}1.27 \\
(1.05)\end{array}$ & $\begin{array}{r}4.43 \\
(2.09)\end{array}$ & $\begin{array}{r}3.55 \\
(2.34)\end{array}$ & $\begin{array}{r}3.46 \\
(2.42)\end{array}$ & 1.00 & $\begin{array}{l}\mathbf{C J} \\
0.112\end{array}$ \\
\hline & & & & & & & & $\begin{array}{l}\text { FW } \\
0.330\end{array}$ \\
\hline
\end{tabular}

Note: Figures in brackets represent the standard deviation across respondents; shaded figures represent the reciprocal of average responses. 
Table 4. Hypothetical Cost-Effectiveness Scenario: Comparing the Cost-Effectiveness of Three Levels of Effect (very high effect, medium and small effect)

\begin{tabular}{|l|c|c|c|}
\hline & $\begin{array}{l}\text { Preschool program } \\
\text { Alternative 1 } \\
\text { (VH-effect) }\end{array}$ & $\begin{array}{l}\text { Preschool program } \\
\text { Alternative 2 } \\
\text { (M-effect) }\end{array}$ & $\begin{array}{l}\text { Preschool program } \\
\text { Alternative 3 } \\
\text { (S-effect) }\end{array}$ \\
\hline $\begin{array}{l}\text { Average cost per } \\
\text { participant }\end{array}$ & $\$ 65,202.30$ & $\$ 32,320.10$ & $\$ 17,413.00$ \\
\hline Overall effectiveness & 70.2 & 60.0 & 55.0 \\
\hline Cost-effectiveness ratio & $\$ 928.81$ & $\$ 538.66$ & $\$ 316.60$ \\
\hline
\end{tabular}

Note: The cost-effectiveness ratio (row 3) is calculated as average cost (row 1) divided by overall effectiveness (row 2). 


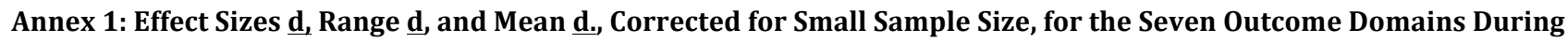
Adolescence

\begin{tabular}{|c|c|c|}
\hline Program + (age at follow-up) & Component (Major component) & Effect size \\
\hline $\begin{array}{l}\text { Abecedarian Project } \\
\text { (20 Yrs) - Campbell et al. (2002) }\end{array}$ & $\begin{array}{l}\text { CBCC (SPP) } \\
\text { Preschool (5 years) vs. no preschool control }\end{array}$ & $\begin{array}{l}\text { ES }(\underline{\mathrm{d}}=0.44) ; \mathrm{CD}(\underline{\mathrm{d}}=0.47) ; \mathrm{D} \\
(\underline{\mathrm{d}}=0.49) ; \mathrm{SED}(\underline{\mathrm{d}}=0.43) ; \mathrm{CJ}(\underline{\mathrm{d}} \\
=0.21)\end{array}$ \\
\hline $\begin{array}{l}\text { Abecedarian Project (15 Yrs) - } \\
\text { Campbell and Ramey (1995) }\end{array}$ & $\begin{array}{l}\text { CBCC; (SPP) } \\
\text { Preschool (5 years) vs. no preschool control }\end{array}$ & $\mathrm{CD}(\underline{\mathrm{d}}=0.74)$ \\
\hline $\begin{array}{l}\text { Abecedarian Project (15 Yrs) - } \\
\text { Campbell and Ramey (1995) }\end{array}$ & $\begin{array}{l}\text { CBCC (SPP) } \\
8 \text { years of intervention }-(5 \text { yrs from infancy } \\
\text { to kindergarten and } 3 \text { years in primary } \\
\text { grades) vs. control }\end{array}$ & ES $(\underline{d}=0.69) ; C D(\underline{d}=0.59)$ \\
\hline $\begin{array}{l}\text { Abecedarian Project } \\
\text { (12 Yrs) - Campbell and Ramey } \\
\text { (1994) }\end{array}$ & $\begin{array}{l}\text { CBCC (SPP) } \\
8 \text { years of intervention }-(5 \text { yrs from infancy } \\
\text { to kindergarten and } 3 \text { years in primary } \\
\text { grades) vs. control }\end{array}$ & $\mathrm{ES}(\underline{\mathrm{d}}=0.79) ; \mathrm{CD}(\underline{\mathrm{d}}=0.40)$ \\
\hline $\begin{array}{l}\text { Abecedarian Project ( } 12 \\
\text { Yrs)- Campbell and Ramey } \\
\text { (1994) }\end{array}$ & $\begin{array}{l}\text { CBCC (SPP) } \\
\text { Preschool (5 years) vs. no preschool control }\end{array}$ & $\mathrm{ES}(\underline{\mathrm{d}}=0.24) ; \mathrm{CD}(\underline{\mathrm{d}}=0.53)$ \\
\hline $\begin{array}{l}\text { Chicago Child-Parent Center (CPC) } \\
\text { (11 Yrs) - Reynolds (1994) }\end{array}$ & $\begin{array}{l}\text { (SPP); CBCC; FSS } \\
\text { Preschool only vs. control }\end{array}$ & $\begin{array}{l}\operatorname{ES}(\underline{d}=-0.12) ; \operatorname{CD}(\mathrm{d}=0.18) ; \\
\operatorname{SED}(\mathrm{d}=0.12) ; \mathrm{FW}(\mathrm{d}=0.11)\end{array}$ \\
\hline $\begin{array}{l}\text { Chicago Child-Parent Center (CPC) } \\
\text { (11 Yrs) - Reynolds (1994) }\end{array}$ & $\begin{array}{l}\text { (SPP); CBCC; FSS } \\
\text { Preschool (6 yrs - preschool to grade 3) vs. } \\
\text { control }\end{array}$ & $\begin{array}{l}\operatorname{ES}(\underline{\mathrm{d}}=-0.39) ; \operatorname{CD}(\underline{\mathrm{d}}=0.29) ; \\
\operatorname{SED}(\underline{\mathrm{d}}=0.11) ; \mathrm{FW}(\underline{\mathrm{d}}=0.11)\end{array}$ \\
\hline $\begin{array}{l}\text { Chicago Child-Parent Center (CPC) } \\
\text { (20 Yrs) - Reynolds et al. (2001) }\end{array}$ & $\begin{array}{l}\text { (SPP); CBCC; FSS } \\
\text { Preschool (6 yrs - preschool to grade 3) vs. } \\
\text { control }\end{array}$ & ES $(\underline{d}=0.16) ; C J(\underline{d}=0.20)$ \\
\hline $\begin{array}{l}\text { Early Training Project } \\
\text { (18 Yrs) - Lazar et al. (1982) }\end{array}$ & $\begin{array}{l}\text { (SPP); HV } \\
\text { Preschool vs. control }\end{array}$ & $\begin{array}{l}\operatorname{ES}(\underline{d}=0.29) ; \operatorname{CD}(\underline{d}=0.16) ; \\
\operatorname{SED}(d=0.65) ;\end{array}$ \\
\hline $\begin{array}{l}\text { Early Training Project } \\
\text { (13 Yrs) - Lazar et al. (1982) }\end{array}$ & $\begin{array}{l}\text { (SPP); HV } \\
\text { Preschool vs. control }\end{array}$ & $\mathrm{CD}(\underline{\mathrm{d}}=0.46)$ \\
\hline $\begin{array}{l}\text { Early Training Project } \\
\text { (11 Yrs) - Gray and Klaus (1970) }\end{array}$ & $\begin{array}{l}\text { (SPP); HV } \\
\text { Preschool vs. control. }\end{array}$ & $\mathrm{CD}(\underline{\mathrm{d}}=0.51)$ \\
\hline $\begin{array}{l}\text { Elmira Nurse Home Visitation } \\
\text { Program } \\
\text { (15 Yrs) - Eckenrode et al. (2000) }\end{array}$ & $\begin{array}{l}\text { (HV); FSS } \\
\text { Program vs. control }\end{array}$ & $\mathrm{FW}(\underline{\mathrm{d}}=0.38)$ \\
\hline $\begin{array}{l}\text { Learning to Learn } \\
\text { (12 Yrs) - Sprigle and Shaefer (1985) }\end{array}$ & $\begin{array}{l}\text { (SPP) } \\
\text { Learning to Learn (preschool through grade } \\
\text { 1) vs. Head Start }\end{array}$ & ES $(\underline{d}=0.94) ; C D(\underline{d}=0.51)$ \\
\hline $\begin{array}{l}\text { Louisville experiment } \\
\text { (13 Yrs) - Miller and Bizzell (1983) }\end{array}$ & $\begin{array}{l}\text { (CBCC) } \\
\text { Bereiter-Engelmann Preschool vs. Control }\end{array}$ & $\mathrm{CD}(\underline{\mathrm{d}}=0.24)$ \\
\hline $\begin{array}{l}\text { Mother-Child Home program (17 } \\
\text { Yrs) - Levenstein et al. (1998) }\end{array}$ & $\begin{array}{l}\text { (FSS) } \\
\text { Program vs. control }\end{array}$ & ES $(\underline{d}=0.34)$ \\
\hline $\begin{array}{l}\text { Perry Preschool Program } \\
\text { (19 Yrs) - Berrueta-Clement et al. } \\
(1984)\end{array}$ & $\begin{array}{l}\text { (SPP); HV } \\
\text { Program vs. control }\end{array}$ & $\mathrm{D}(\underline{\mathrm{d}}=0.645) ; \mathrm{CJ}(\underline{\mathrm{d}}=0.41)$ \\
\hline $\begin{array}{l}\text { The Syracuse University Family } \\
\text { Development Research Program } \\
\text { (15 Yrs) - Lally et al. (1988) }\end{array}$ & $\begin{array}{l}\text { HV; CBCC; }(\mathrm{FSS}) \\
\text { Program vs. control }\end{array}$ & $\begin{array}{l}\text { ES }(\underline{\mathrm{d}}=0.82) ; \mathrm{SED}(\underline{\mathrm{d}}=0.40) ; \\
\mathrm{SP}(\underline{\mathrm{d}}=0.45) ; \mathrm{CJ}(\underline{\mathrm{d}}=0.48) ; \mathrm{FW} \\
(\mathrm{d}=0.43)\end{array}$ \\
\hline $\begin{array}{l}\text { Parent-Child Development Centres } \\
\text { (PCDCs) (15 Yrs) - Johnson (2006) }\end{array}$ & $\begin{array}{l}\text { (SPP); HV; FSS; PE } \\
\text { Houston PCDC vs. control } \\
5 \text { yr program infancy }-5 \text { yrs }\end{array}$ & $\operatorname{SED}(\underline{d}=0.23)$ \\
\hline $\begin{array}{l}\text { Parent-Child Development Centres } \\
\text { (PCDCs) (12 Yrs) - Johnson and } \\
\text { Blumenthal (2004) }\end{array}$ & $\begin{array}{l}\text { (SPP); HV; FSS; PE } \\
\text { Houston PCDC vs. control } \\
5 \text { yr program infancy }-5 \text { yrs }\end{array}$ & $\begin{array}{l}\text { ES }(\underline{d}=0) ; C D(\underline{d}=0.36) ; \text { SED } \\
(\underline{d}=0) ; S P(\underline{d}=0.32) ; F W(\underline{d}= \\
0)\end{array}$ \\
\hline $\begin{array}{l}\text { Project Follow Through (Brooklyn } \\
\text { Project) - Meyer (1984) }\end{array}$ & $\begin{array}{l}\text { (SPP); HV } \\
\text { Direct Instruction vs. control } \\
\text { Preschool through grade } 3\end{array}$ & ES $(\underline{d}=0.38) ; C D(\underline{d}=0.42)$ \\
\hline
\end{tabular}




\begin{tabular}{|l|l|l|}
\hline $\begin{array}{l}\text { Elmira Nurse Home Visitation } \\
\text { Program (15 Yrs) - Olds et al. (1998) }\end{array}$ & $\begin{array}{l}\text { (HV); FSS } \\
\text { Program vs. control }\end{array}$ & $\begin{array}{l}E S(\underline{\mathrm{d}}=0.46) ; \mathrm{D}(\underline{\mathrm{d}}=0.28) ; \mathrm{CJ} \\
(\underline{\mathrm{d}}=0.32)\end{array}$ \\
\hline $\begin{array}{l}\text { Range } \underline{\mathrm{d}} \\
\text { ES }(\underline{\mathrm{d}}=0.00-0.94) ; \mathrm{CD}(\underline{\mathrm{d}}=0.16-0.74) ; \mathrm{SED}(\underline{\mathrm{d}}=0.00-0.65) ; \mathrm{D}(\underline{\mathrm{d}}=0.28-0.65) ; \mathrm{SP}(\underline{\mathrm{d}}=0.32-0.45) ; \mathrm{CJ}(\underline{\mathrm{d}}=0.20-0.48) ; \mathrm{FW} \\
(\underline{\mathrm{d}}=0-0.43)\end{array}$ \\
$\begin{array}{l}\text { Mean } \underline{\mathrm{d}} . \\
\text { ES }(\underline{\mathrm{d}}=0.532) ; \mathrm{CD}(\underline{\mathrm{d}}=0.334) ; \mathrm{SED}(\underline{\mathrm{d}}=0.148) ; \mathrm{D}(\underline{\mathrm{d}}=0.39) ; \mathrm{SP}(\underline{\mathrm{d}}=0.373) ; \mathrm{CJ}(\underline{\mathrm{d}}=0.244) ; \mathrm{FW}(\underline{\mathrm{d}}=0.204)\end{array}$ \\
\hline
\end{tabular}

Note: 1 . The corresponding variance, inverse variance, CI (confidence interval) Lower and Upper (95\%) are available in Manning (2008). 2. ES = educational success; $C D=$ cognitive development; $S E D=$ social emotional development; $\mathrm{D}=$ deviance; $\mathrm{SP}=$ social participation; $\mathrm{CJ}=$ criminal justice; $\mathrm{FW}=$ family wellbeing. 3 . $\mathrm{SPP}=$ structured preschool programs; $\mathrm{HV}=$ home visitation programs; $\mathrm{CBCC}=$ centre based childcare/developmental day care; FSS = family/parenting support; and $\mathrm{PE}=$ parent education programs. 


\section{Notes}

${ }^{\mathbf{i}}$ The broad domain of community risks is disaggregated into individuals living within a neighbourhood that: is impoverished, has higher than average crime rates, has large rates of public housing, has limited social service facilities, and is culturally and linguistically diverse.

ii Characteristics of family risks include: families with high levels of social and economic disadvantage (e.g. lower than average median weekly household income, low rates of high school completion by parents, higher than average rates of single parent families and marital discord, punitive child-rearing practices, high unemployment, and socially isolated due to cultural and linguistic barriers).

${ }^{\text {iii }}$ Peer risks are disaggregated into negative peer pressure or modelling and possible peer rejection.

${ }^{\text {iv }}$ Individual risks include early learning difficulties and possible early behaviour problems.

v A detailed discussion of Cohen's effect sizes is provided in Manning (2008). 